\title{
Hydrothermal crystal growth of $\alpha$-quartz: new specificities correlated to applications
}

\section{G. DEMAZEAU and F. LAFON}

Laboratoire de Chimie du Solide du CNRS et Interface Hautes Pressions, LCS-CNRS - ENSCPB, Université Bordeaux I, 33405 Talence cedex, France

\begin{abstract}
: $\alpha$-quartz is mainly used for high frequencies devices, due to its piezoelectric properties. The development of higher frequencies than before for many applications leads to new requirements concerning the material (lowest concentration of physico-chemical and structural defects) and consequently to its crystal-growth.
\end{abstract}

$\alpha$-quartz, due to its piezoelectric properties has led to the development of either industrial devices and consumer equipments [1] (Table).

\begin{tabular}{|c|l|}
\hline Industrial equipment & $\begin{array}{l}\text { Radiocommunication, cable communication, electronic } \\
\text { applications, measurement equipment, pager, security } \\
\text { system (alarm)... }\end{array}$ \\
\hline Consumer equipment & Electronic handy calculator, watch clock, timer, cable \\
& TV, color TV, video recorder, RF converter, tranceiver, \\
& radio equipment, microphone, electronic appliance, \\
& microphone, electronic appliance, microcomputer and \\
& computer terminal, TV-game machine, telephone, copy \\
& machine... \\
\hline
\end{tabular}

Main Piezoelectric Applications of $\alpha$-quartz Crystal (from Taki)

The $\alpha \rightarrow \beta$ transition taking place close to $573^{\circ} \mathrm{C}$, the synthesis of $\alpha$-quartz single crystals requires a low-temperature crystal-growth process. This condition has led to the development of the hydrothermal process (Fig.). 


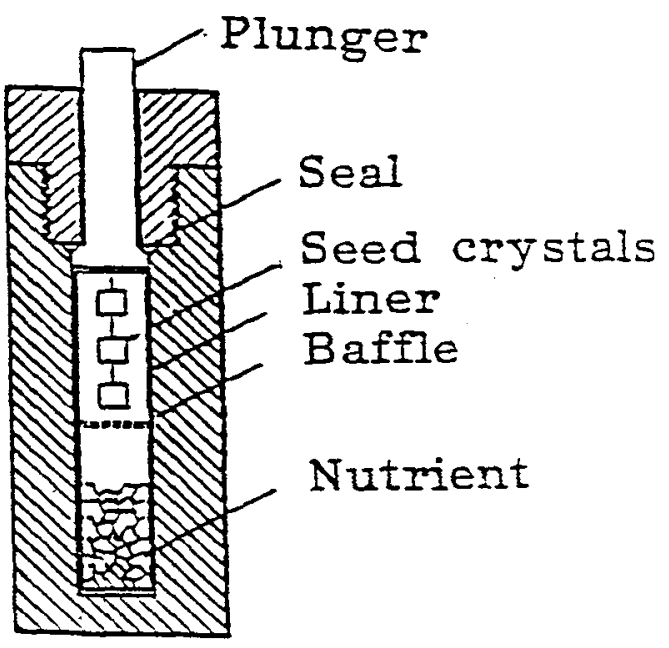

Reaction vessel used for the hydrothermal quartz growth

The use of pressure increase the solubility of the nutrient in the temperature domain selected for the crystal-growth $\left(\mathrm{T} \approx 400^{\circ} \mathrm{C}\right)$. The solvents, conventionnaly used, are a molar solution of $\mathrm{NaOH}$ or $\mathrm{Na}_{2} \mathrm{CO}_{3}$. A gradient of temperature $\Delta \mathrm{T}$ between the nutrient and the seeds allows the transportation of $\mathrm{SiO}_{2}$ as complex anions or polyanions.

Direct measurements on hydrothermal solutions in the crystal-growth conditions of $\alpha-\mathrm{SiO}_{2}$ are needed to establish exactly the nature of such anionic species [2].

The cultured $\alpha$-quartz single crystals are characterized by chemical and physical defects $[1,2]$.

\section{ANALYSIS OF THE DEFECTS OBSERVED IN SYNTHETIC $\alpha-\mathrm{SIO}_{2}$ SINGLE}

\section{CRYSTALS}

Roughly such defects can be classified into two groups :

- the physico-chemical defects,

- the structural defects.

\subsection{The physico-chemical defects}

They are mainly induced by the nature of the nutrient of the solvent and also the chemical contamination of the solution by the metal constituting the reaction vessel. 


\section{The inclusions}

They are constituted by a solid or a liquid phase inserted in the $\alpha-\mathrm{SiO}_{2}$ lattice.

Concerning the solid phase, the most common inclusion is the complex silicate $\mathrm{NaFe}(\mathrm{III}) \mathrm{Si}_{2} \mathrm{O}_{6}$ (acmite). Its formation results from the chemical attack of the reaction vessel (walls iron-alloys) by the alcaline solution $\left(\mathrm{NaOH}\right.$ or $\left.\mathrm{Na}_{2} \mathrm{CO}_{3}\right)$ used as solvent.

\section{The etch-channels}

Such defects are also called etch pipes or tunnels [4-6].

The etch rate along this channel is very much higher than that characterizing the bulk-material. The formation of these defects are correlated to that of dislocations.

\section{Chemical substitutions into the $\alpha$-quartz lattice}

These substitutions are induced by the similarity of cationic or anionic sizes between $\mathrm{Si}^{4+}, \mathrm{O}^{2-}$, $\mathrm{Al}^{3+}$ (or other trivalent cation able to accept the tetrahedral coordination) and $\mathrm{OH}^{-}$.

$$
\begin{aligned}
& \mathrm{O}^{2-} \rightarrow \mathrm{OH}^{-} \\
& \mathrm{Si}^{4+} \rightarrow \mathrm{Al}^{3+}
\end{aligned}
$$

The formation of such a defect is in particular help by the basicity of the solvent $\left(\mathrm{OH}^{-}\right.$ concentration).

\section{Interstitial cations}

In some thermodynamical conditions different cations (in particular $\mathrm{Li}^{+}$) can be in interstitial positions, in particular for compensating the $\mathrm{Si}^{4+} \rightarrow \mathrm{M}^{3+}$ cationic substitution into the $\mathrm{SiO}_{2}-\alpha$ lattice.

\subsection{The structural defects}

The main nature of these defects are dislocations. Their origin can be generally due to foreign particles, thermodynamical parameters governing the crystal growth or hydrodynamic conditions inside the reaction vessel..

\section{2/ QUALIFICATIONS REQUIRED FOR APPLICATIONS}

In a piezoelectric resonator, electrical energy and mechanical energy are interconverted [1]. In such a schema, a resonator can be equivalent to a circuit consisting of an induction, a resistance and two capacitances. 
$Q$ is defined as : $Q=\frac{|x|}{R}$ :

$\mathrm{x}$ is the inductive or capacitive reactance at resonance,

$R$ is the resistance.

$\mathrm{Q}$ can be considered as the inverse of the fraction of the energy lost per cycle. The highest values of $Q$ are required in order to prevent lost of energy into incoherent phonons.

The acoustic $Q$ for natural $\alpha-\mathrm{SiO}_{2}$ crystal are close to 1 to $3.10^{6}$ while for synthetic crystals such a value drop down to $2 \cdot 10^{5}-1 \cdot 10^{6}$. The analysis of such a phenomenon has led to correlate such a $\mathrm{Q}$ value to infrared adsorbtion at $2.86 \mu \mathrm{m}$ corresponding to an $\mathrm{OH}$ stretch frequency [6-8]. This adsorbtion could be induced both by the presence of $\mathrm{H}_{2} \mathrm{O}$ (as inclusion for example) or the anionic substitution $\mathrm{O}^{2-} \rightarrow \mathrm{OH}^{-}$into the lattice, this substitution being compensated by a cationic one $\mathrm{Si}^{4+} \rightarrow \mathrm{Al}^{3+}$ or $\mathrm{Si}^{4+} \rightarrow \mathrm{Fe}^{3+}$.

During these last twenty years, the main requirement for growing $\alpha-\mathrm{SiO}_{2}$ single crystal was to improve $\mathrm{Q}$, and to get a low concentration of physico-chemical and structural defects.

\section{3/ NEW CONSTRAINTS FOR DEVELOPING HIGH FREQUENCY DEVICES}

The development of high frequency devices $(24 \mathrm{MHz} \rightarrow 100 \mathrm{MHz}$ and more), induces strong constraints concerning the shaping of the $\alpha-\mathrm{SiO}_{2}$ material.

If for $24 \mathrm{MHz}$ the thickness of the sheet is close to $70 \mu \mathrm{m}$, in the domain of $100 \mathrm{MHz}$ such a thickness can drop down to 6-7 $\mu \mathrm{m}$. This requirement is important for the crystal-growth of $\alpha$-quartz, the size of the defects being of the same order. Consequently for the solid state chemist, the elaboration of single-crystals with a very low concentration of defects appears to be a new goal.

\subsection{Role of the defects on the applications}

The existence of defects in synthetic quartz crystals leads to critical modifications of resulting devices [9].

The inclusions can be assimilated to a zone of discontinuity, the acoustic wave is propagated in another solid.

The $\mathrm{OH}$ concentration induce to a large decrease of the acoustic coefficient $\mathrm{Q}$. The substitution $\mathrm{O}^{2-} \rightarrow \mathrm{OH}^{-}$being coupled with the cationic one $\left(\mathrm{Si}^{4+} \rightarrow \mathrm{M}^{3+}\right)$, the $\mathrm{M}^{3+}$ impurities can play an important rôle concerning the ageing process of the device and its behaviour versus ionizing radiations. 
The dislocations inducing local stresses, a modification of the local electric field compared to the applied one can be observed.

\subsection{New developments in $\alpha-\mathrm{SiO}_{2}$ crystal-growth}

Considering the analysis of the main defects generally observed in $\alpha$-quartz lattice, different parameters can be defined for obtaining a significative improvement of the single crystal quality :

a) the purity of the solvent,

b) the development of new solvents able to reduce the anionic and cationic substitutions $[10,11]$,

c) the increase of pressure domain [12],

d) the strict control of the thermodynamical parameters $P, T, \Delta T$ governing the process,

e) a reductions of the $\Delta T$ value,

f) an optimization of all parameters governing the thermodynamical parameters and the structure of the reaction vessel [13].

\section{CONCLUSION}

The development of new devices results in the major case of the overlap of competences between solid state chemistry, physics and ingeniering. $\alpha$-quartz is a old piezoelectric material if we consider the first experiments devoted to the crystal-growth of synthetic quartz [14]. The futur developments of new-devices based on high frequencies require to reach the intrinsic properties of such a material. Consequently, the improvement of single-crystals quality appears a goal in Materials Science [15].

\section{References}

1) S. Taki, Prog. Crystal Growth and Charact., 23, 313, 1991.

2) R.A. Laudise and R.L. Barns, I.E.E.E. Transactions on Ultrasonics Ferroelectrics and Frequency Control, 35(3), 277, 1988.

3) G.W. Arnold, "Defects in quartz crystals", Proc. 11th Ann. Symp. Freq. Contr., 112, 1957.

4) J.W. Nielsen and F.G. Foster, Am. Mineral, 45, 299, 1960..

5) W.J. Spencer and K. Haruta, J. Appl. Phys., 37, 2557, 1966.

6) D.M. Dood and D.B. Fraser, J. Phys. Chem. Solids, 26, 673, 1965.

7) J.C. Brice and M. Cole, Proc. 22nd Ann. Symp. Freq. Contr., 1, 1978.

8) B. Sawyer, Proc. 37th Ann. Symp. Freq. Contr., 151, 1983.

9) J. Ashara, K. Takazawa, E. Yazaxi, J. Okuda and N.A. Asanu, Proc. 28th Ann. Symp. Freq. Contr., 117, 1974. 
10) M. Hosaka and S. Taki, J. Crystal Growth, 52, 837, 1981.

11) M. Hosaka and S. Taki, J. Crystal Growth, 53, 542, 1981.

12) F. Lafon and G. Demazeau, High Pressure Research (in press).

13) G.R. Johnson, R.A. Irvine and J.W. Foise, Proc. 43rd. Ann. Freq. Contr. Symp., 447, 1989.

14) G. Spezia, Accad. Sci. di Torine, 44, 95, 1908.

15) R.A. Laudise and J.W. Nielsen, Solid State Physics, 12, 149, 1961 